\title{
Effects of Aerodynamic downforce on Vehicle Control and Stability
}

\author{
Sidhant Konwar Roy ${ }^{1}$ and \\ Abhishek Mahesh Sharma ${ }^{2}$ \\ ${ }^{1-2} R V$ College of Engineering \\ Isidhantkr9@gmail.com, \\ 21abhishekm14@gmail.com
}

\begin{abstract}
This paper deals with the analysis of vehicle handling with the variation of downforce. A vehicle with aero package were taken and the values of aerodynamic downforce and front downforce distribution for different front and rear ride heights were taken. This was followed by the generation of yaw moment diagram at original ground clearance of $30 \mathrm{~mm}$. Aero map data were collected and individual yaw moment diagrams were collected from which vehicle handling parameters are noted. Different contour plots were made to understand the variation of vehicle handling with different ride heights (aerodynamics downforce and downforce distribution). The paper concludes with the sensitivity study where effects of aerodynamic downforce were recorded on vehicle control and stability.
\end{abstract}

Keywords: vehicle dynamics, vehicle handling parameters, aero-map, yaw moment diagram, sensitivity study

\section{Introduction}

Aerodynamics and vehicle dynamics are inter-related. Change in aerodynamics in a vehicle brings about a massive change in vehicle handling. Aerodynamic loads (drag, downforce and side force) can change the vehicle behaviour. Understanding the fundamentals of vehicle dynamics is key in order to predict vehicle handling. Any change in vehicle feature will impact vehicle behaviour. Similar to aircrafts, when vehicle aerodynamic characteristics are altered, vehicle behaviour will also be affected. Hence to ensure that there is a positive change in vehicle behaviour due to change in aerodynamic characteristics, vehicle dynamics is important. Factors affecting vehicle dynamics include: aerodynamics, powertrain, tires, weight distribution and suspension. This paper deals with the effect of aerodynamics on vehicle control and stability. The parameters of aerodynamics that affect vehicle handling include: aerodynamics forces (downforce. drag force and side force) and the distribution of these forces about the 4 wheels. Aerodynamics can cause two types of change in vehicle behavior: positive change (improves handling) and negative change (deteriorates handling). Hence aerodynamics must be designed to produce a positive change in vehicle behavior. Vehicle handling is quantified by 4 key parameters: Grip, Balance, Control and Stability. These vehicle parameters are found from the yaw moment diagram. For varied amounts of steering angle and body slip angle, a graph between yaw moment in the $\mathrm{y}$ axis and lateral acceleration in the $\mathrm{x}$ axis is called a yaw moment diagram. At a given vehicle speed and configuration, the yaw moment diagram depicts the vehicle handling envelope. At a given vehicle configuration, grip is the maximal lateral acceleration produced by the tyres. The yaw moment of the vehicle corresponding to maximum lateral acceleration is called balance. The amount of yaw moment produced by the vehicle when the driver changes the steering angle by one degree is referred to as control. When an external disturbance produces a change in body slip angle of the vehicle by one degree, stability is defined as the quantity of anti-yaw moment produced by the vehicle.

\section{Vehicle Parameters used for Analysis of vehicle controland stability}

Vehicle handling depends on many parameters such as vertical loads on tires, wheelbase, trackwidth, center of gravity and roll center height, suspension setup and aerodynamic forces. Hence, it is crucial to know the vehicle parameters for analysis. In this paper, the vehicle prototype used was from a formula student team with aero package. 
Table 1 shows the vehicle parameters used for the study of the effects of aerodynamic downforce on vehicle control and stability.

Table 1. Vehicle parameters used for the analysis

\begin{tabular}{|c|c|c|c|}
\hline Vehicle Mass & $m$ & 275 & $\mathrm{~kg}$ \\
\hline Fore-Aft Weight Distribution & $F A W D$ & 0.51 & \\
\hline Left-Right Weight Distribution & LRWD & 0.5 & \\
\hline Downforce @ Given Speed & $F d$ & 221.12 & $\mathrm{~N}$ \\
\hline Fore-Aft Downforce Distribution & $F A D D$ & 0.1983 & \\
\hline Left-Right Downforce Distribution & $L R D D$ & 0.5 & \\
\hline Wheelbase & $L$ & 1.6 & $\mathrm{~m}$ \\
\hline Front Trackwidth & $T f$ & 1.25 & $\mathrm{~m}$ \\
\hline Rear Trackwidth & $T r$ & 1.2 & $\mathrm{~m}$ \\
\hline Longitudinal Velocity (constant) & $V x$ & 14 & $\mathrm{~m} / \mathrm{s}$ \\
\hline Front CG Height & $Z c g$ & 0.25 & $\mathrm{~m}$ \\
\hline Front Roll Center Height & $Z f$ & 0.0381 & $\mathrm{~m}$ \\
\hline Rear Roll Center Height & $\mathrm{Zr}$ & 0.0387 & $\mathrm{~m}$ \\
\hline Distance between CG and Roll Axis & $\mathrm{Zcr}$ & 0.2116 & $\mathrm{~m}$ \\
\hline Ackermann Ratio & $\mathrm{AR}$ & 1.15 & \\
\hline
\end{tabular}

\begin{tabular}{|c|c|c|c|c|}
\hline \multicolumn{2}{|c|}{ Aerodynamic Side Force@Given Speed } & Fs & 0 & $N$ \\
\hline \multicolumn{2}{|c|}{ Distance between $C P$ and $C G$} & $d C P C G$ & 0 & $m$ \\
\hline \multirow{4}{*}{ Toe Angle } & Front Left & toeFL & 0 & $\operatorname{deg}$ \\
\hline & Front Right & toeFR & 0 & $\operatorname{deg}$ \\
\hline & Rear Left & toeRL & 0 & deg \\
\hline & Rear Right & toeRR & 0 & $\operatorname{deg}$ \\
\hline \multicolumn{2}{|c|}{ Yaw Moment of Inertia } & $I z$ & 279.24 & $\mathrm{kgm}^{\wedge} 2$ \\
\hline \multicolumn{2}{|c|}{ Pitch Moment of Inertia } & Iy & 175.94 & $\mathrm{kgm}^{\wedge} 2$ \\
\hline \multicolumn{2}{|c|}{ Roll Moment of Inertia } & $I x$ & 103.3 & $\mathrm{kgm}^{\wedge} 2$ \\
\hline \multicolumn{2}{|c|}{ Front Roll Stiffness } & $K f$ & 446 & $\mathrm{Nm} / \mathrm{deg}$ \\
\hline \multicolumn{2}{|c|}{ Rear Roll Stiffness } & $K r$ & 446 & $\mathrm{Nm} / \mathrm{deg}$ \\
\hline \multicolumn{2}{|c|}{ Front Pitch Stiffness } & $K P f$ & 627.5 & $\mathrm{Nm} / \mathrm{deg}$ \\
\hline \multicolumn{2}{|c|}{ Rear Pitch Stiffness } & $K P r$ & 627.5 & $\mathrm{Nm} / \mathrm{deg}$ \\
\hline \multicolumn{2}{|c|}{ Heave Stiffness } & $\mathrm{KHr}$ & 87.9 & $\mathrm{~N} / \mathrm{mm}$ \\
\hline
\end{tabular}

\section{Yaw Moment Diagram of the vehicle}

Yaw moment diagram is a graph between yaw moment (units: $\mathrm{Nm}$ ) in y axis and lateral acceleration (units: $\mathrm{m} / \mathrm{s} 2$ ) in $\mathrm{x}$ axis for different values of steering angle and body slip angle. The yaw moment diagram consists of 2 sets of lines: iso-beta lines and iso-delta lines. Iso-beta line is a line where body slip angle is constant and only steering angle changes along the line. Iso-delta line is a line where steering angle is constant and only body slip angle changes along the line. The yaw moment diagram shows the vehicle handling envelope at a given vehicle speed and vehicle configuration. From the yaw moment diagram, vehicle handling parameters such as grip, balance, control and stability are found. Four-wheel lateral dynamics model is a vehicle dynamics model for analysing vehicle handling while considering all 4 wheels. This is a 3 degree of freedom model where steering angle, body slip angle and yaw rate are the input to the model. Yaw moment diagram is generated by using this model. From the yaw moment diagram, vehicle handling parameters such as grip, balance, control and stability are found. The tip (on the right) of the yaw moment diagram gives 2 vehicle handling parameters called grip and balance. The $\mathrm{x}$ coordinate of the tip indicates grip in $\mathrm{m} / \mathrm{s} 2$ and $\mathrm{y}$ coordinate of the tip indicates the balance in $\mathrm{Nm}$. The change in yaw moment when traversing from one iso-beta line to another iso-beta along the same iso-delta line gives the stability (in Nm/deg) for that steering angle input and for that change in body slip angle. The change in yaw moment when traversing from one iso-delta line to another iso-delta along the same iso-beta line gives the control (in $\mathrm{Nm} / \mathrm{deg}$ ) for that body slip angle input and for that change in steering angle. Fig 1 shows the yaw moment diagram of the vehicle. 


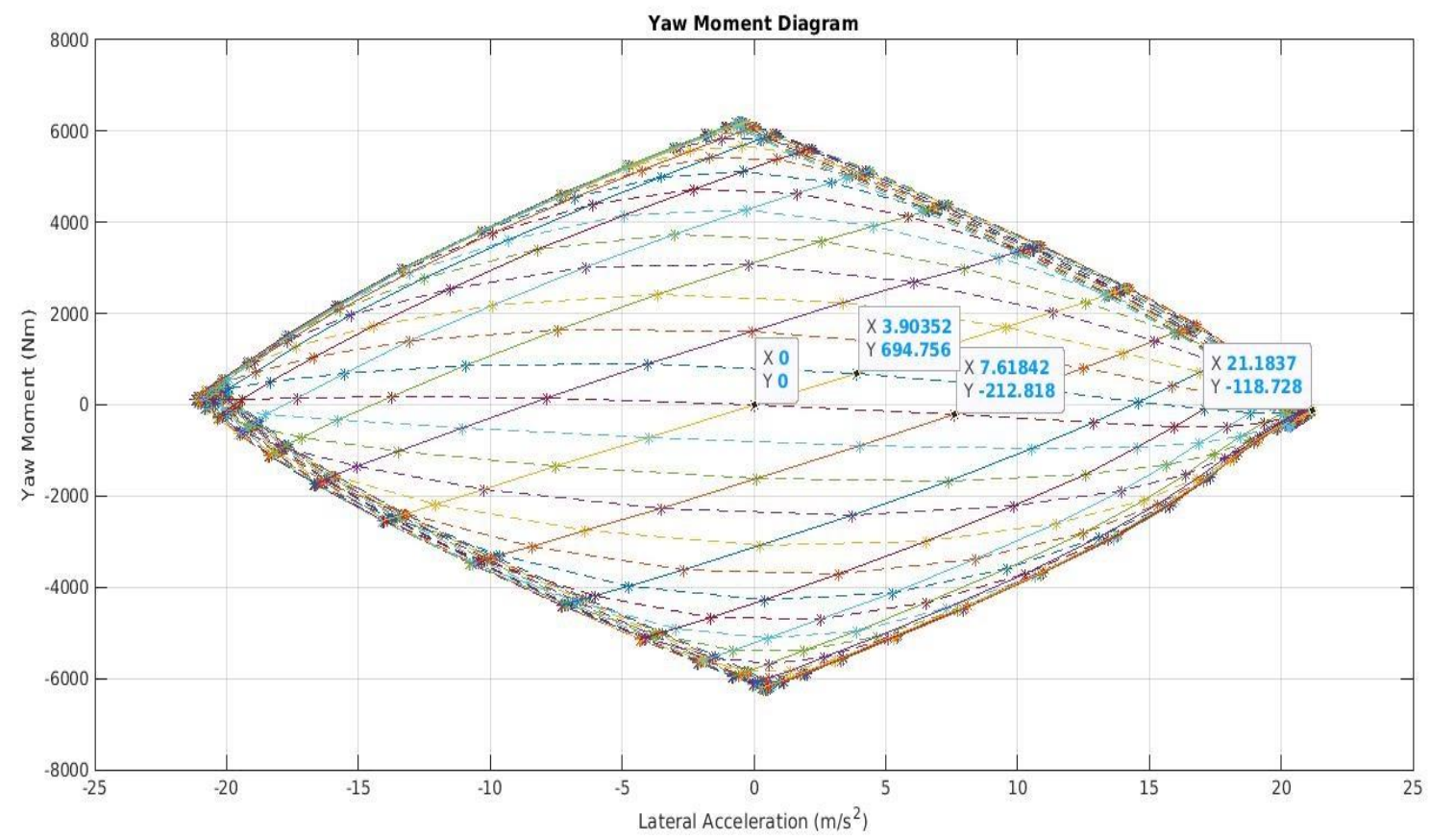

Fig 1. Yaw Moment Diagram

The table 2 below shows vehicle handling parameters of the vehicle

Table 2. Vehicle Handling parameters of the vehicle

\begin{tabular}{|c|c|c|}
\hline Vehicle Handling Parameter & Value & Units \\
\hline Grip & 21.18 & $\mathrm{~m} / \mathrm{s}^{2}$ \\
\hline Balance & -118.73 & $\mathrm{Nm}$ \\
\hline Control & 694.76 & $\mathrm{Nm} / \mathrm{deg}$ \\
\hline Stability & -212.82 & $\mathrm{Nm} / \mathrm{deg}$ \\
\hline
\end{tabular}

\section{Generation of Aero map data of the vehicle}

An "aero map" is a basic graph that expresses aerodynamic forces vs ride height created by wind tunnel Engineers. Drag, downforce, and relative distribution are all measured on a variety of front and rear ride heights. To produce an aero map, a baseline CF D simulation is performed at a specific attitude that is most typically experienced across a lap. Then, by adjusting parameters such as front and rear ride height, many CFD simulations are run. Aero maps can be used to show aero balance across the attitude range as well as analyse the sensitivity of aero packages to various parameters. Instead of focusing just on straight line performance, this technique allows an aero package to be changed to become less sensitive to dynamic situations on the track. Ride height is the parameter used in the paper to generate the aero map. Set of various ride height configurations were taken for which CFD simulations were done and the results (downforce and downforce distribution) were noted. Table 3 shows the variation of downforce with front and rear ride height and Table 4 shows the variation of downforce distribution with front and rear ride height. 
Table 3. Aerodynamic downforce acting on the vehicle

\begin{tabular}{|c|c|c|c|c|c|}
\hline Front (mm) & $\mathbf{1 0}$ & $\mathbf{2 0}$ & $\mathbf{3 0}$ & $\mathbf{4 0}$ & $\mathbf{5 0}$ \\
\hline Rear (mm) & \multicolumn{5}{|c|}{ Downforce (N) } \\
\hline $\mathbf{1 0}$ & 221.1185 & 223.0533 & 207.9157 & 218.769 & 211.8866 \\
\hline $\mathbf{2 0}$ & 232.58 & 218.1834 & 220.9248 & 226.0708 & 222.6891 \\
\hline $\mathbf{3 0}$ & 225.65 & 228.0406 & 224.8718 & 220.0327 & 218.8309 \\
\hline $\mathbf{4 0}$ & 252.06 & 230.486 & 217.5315 & 222.0704 & 223.1712 \\
\hline $\mathbf{5 0}$ & 266.1194 & 237.7242 & 228.43 & 222.786 & 225.904 \\
\hline
\end{tabular}

Table 4. Aerodynamic downforce distribution of the vehicle

\begin{tabular}{|c|c|c|c|c|c|}
\hline Front (mm) & $\mathbf{1 0}$ & $\mathbf{2 0}$ & $\mathbf{3 0}$ & $\mathbf{4 0}$ & $\mathbf{5 0}$ \\
\hline Rear (mm) & \multicolumn{5}{|c|}{ Front Downforce Distribution (\%) } \\
\hline $\mathbf{1 0}$ & 21.79 & 20.1 & 19.83 & 19.23 & 18.85 \\
\hline $\mathbf{2 0}$ & 26.27 & 24.76 & 23.94 & 21.74 & 20.88 \\
\hline $\mathbf{3 0}$ & 29.88 & 27.68 & 26.58 & 24.75 & 22.53 \\
\hline $\mathbf{4 0}$ & 33.16 & 29.95 & 28.63 & 26.86 & 24.05 \\
\hline $\mathbf{5 0}$ & 35.71 & 31.56 & 30.37 & 28.33 & 26.62 \\
\hline
\end{tabular}

\section{Aerodynamiceffects on vehicle control and stability}

Using the yaw moment diagram, vehicle handling parameters for different ride heights were found. The main purpose of using aero map data is to understand the variation of vehicle handling parameters with ride heights as for different ride heights, there are different set of aerodynamic downforce values and front downforce distribution values.

The Fig 2 shown depicts the variation of balance with ride heights. From the plot, it is evident that understeer characteristics increase when the front ride height increases. Similarly, when rear ride height increases, oversteer characteristics increase.

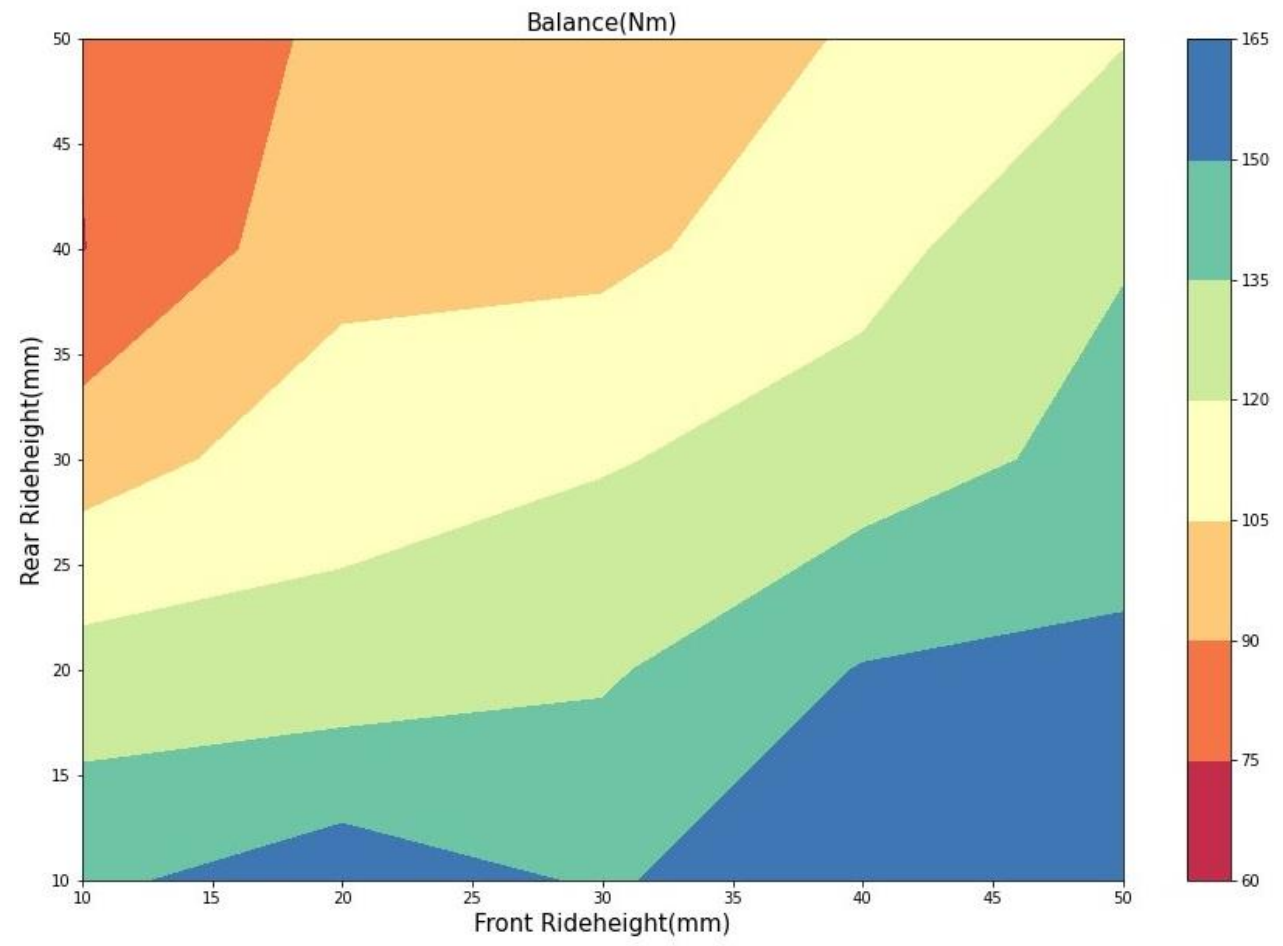

Fig 2 Variation of Balance with ride heights

The Fig 3 shown below depicts the variation of control with ride heights. As seen in the plot, vehicle control decreases when the front ride height increases. Similarly, when rear ride height increases, vehicle control increases. 


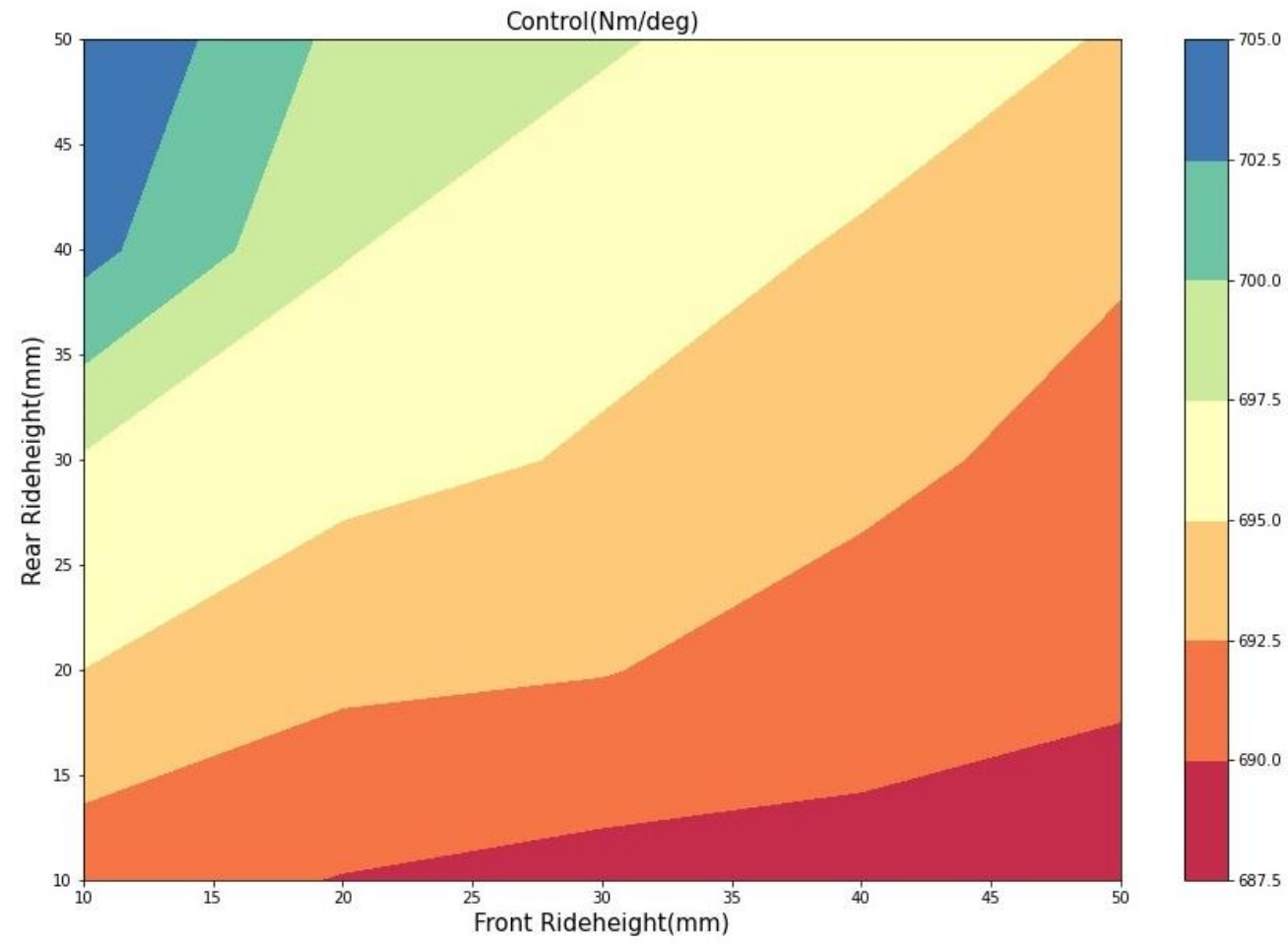

Fig 3 Variation of Control with ride heights

The Fig 4 shown below depicts the variation of grip with ride heights. From the plot, the grip decreases and then increases when the front ride height increases. Similarly, when rear ride height increases, grip increases.

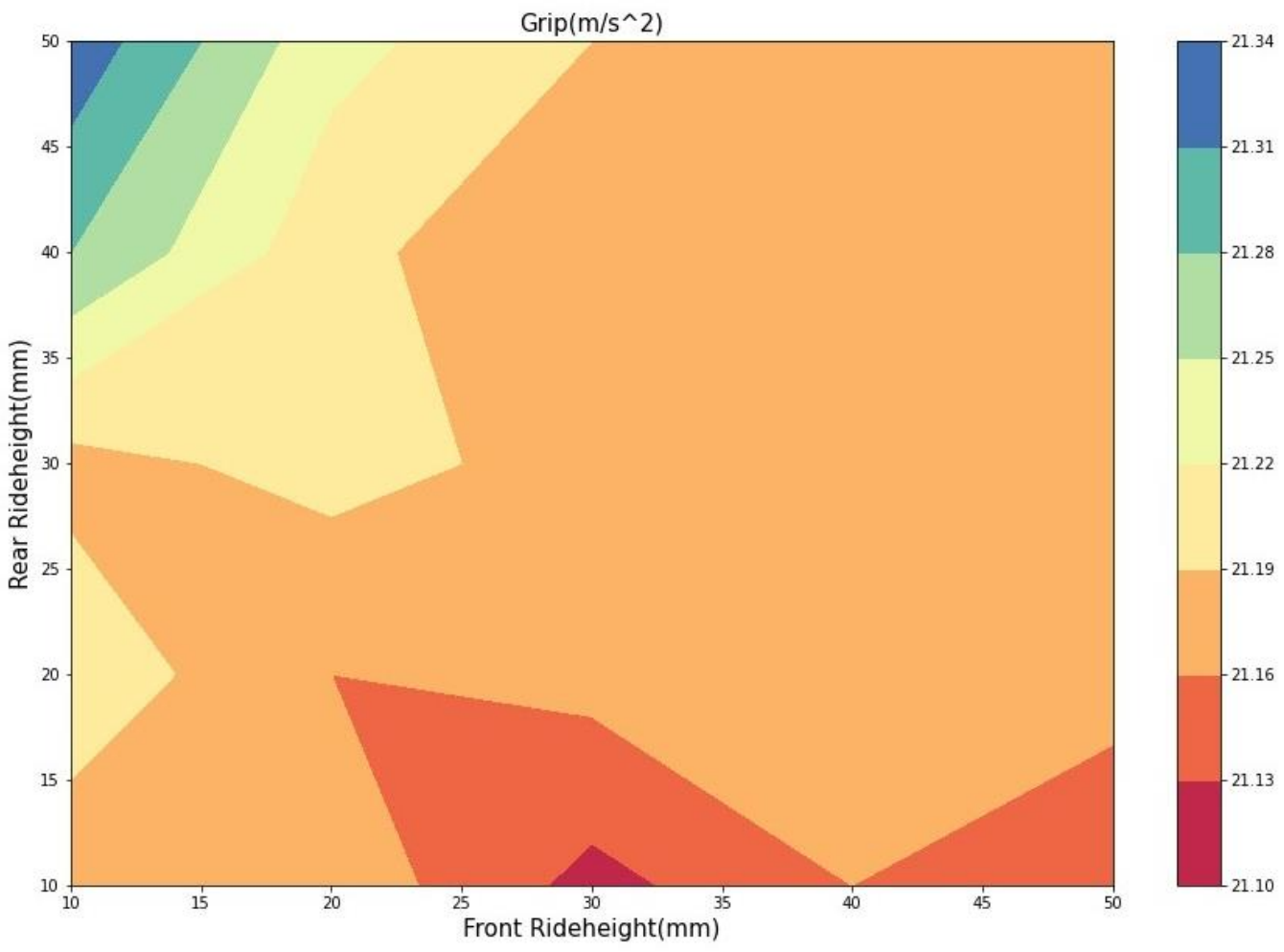

Fig 4 Variation of Grip with rideheights

The Fig 5 shown depicts the variation of stability with ride heights. As seen in the plot, stability increases or manoeuvrability decreases when the front ride height increases. Similarly, when rear ride height increases, stability decreases and manoeuvrability increases. 


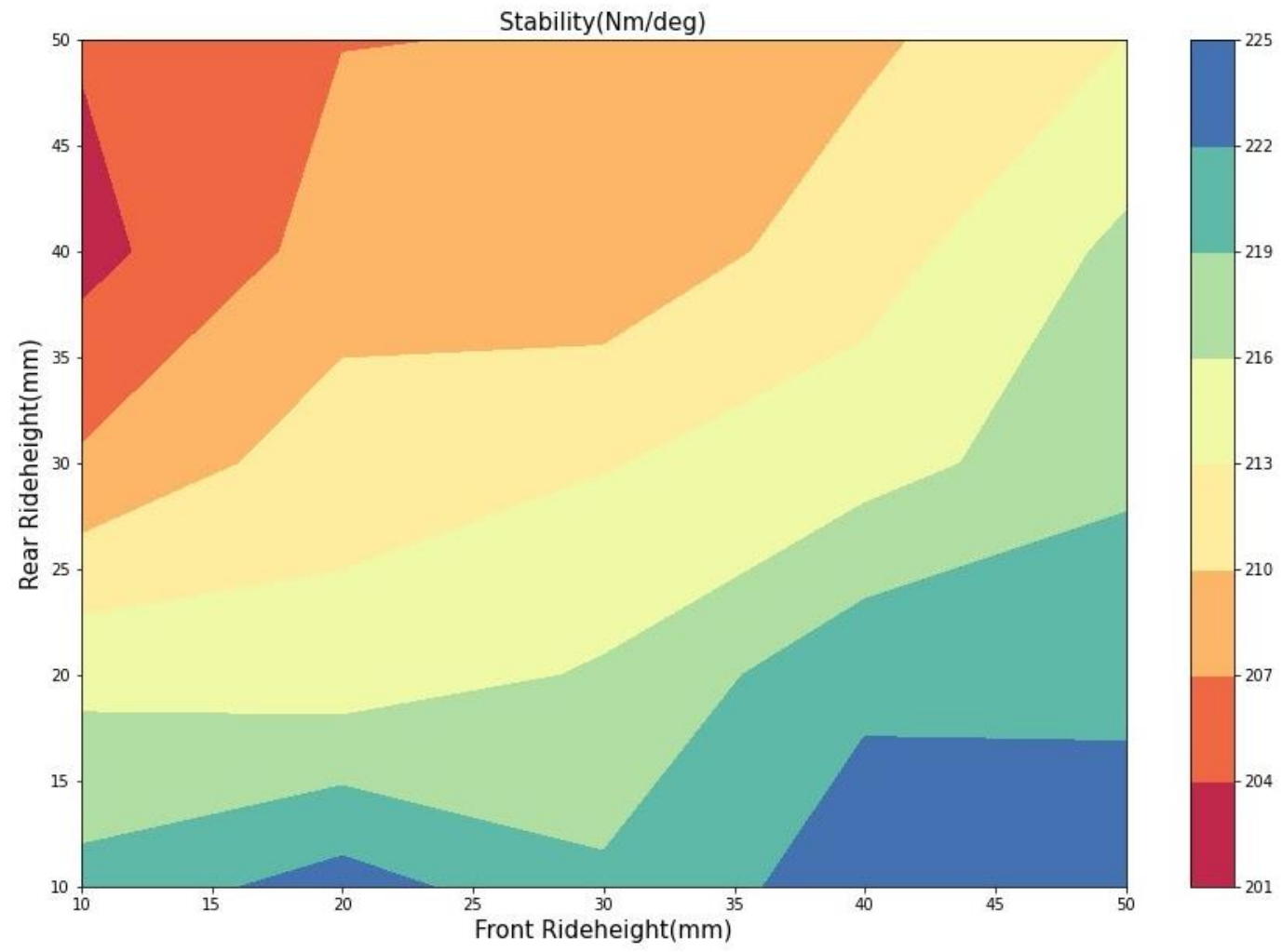

Fig 5. Variation of stability with ride heights

\section{Sensitivity Study}

Sensitivity study is a method of understanding how changing certain vehicle parameters will affect the vehicle stability and handling. Sensitivity study parameters used in the paper includes $33 \%$ increase in downforce, front downforce distribution, front and rear ride heights. Table 5 shows the vehicle handling parameters for $33 \%$ increase in downforce, front downforce distribution, front and rear ride heights. Table 6 shows the percentage change in vehicle handling parameters for 33\% increase in downforce, front downforce distribution, front and rear ride heights.

Table 45 Vehicle handling parameters used in Sensitivity study

\begin{tabular}{|c|c|c|c|c|}
\hline & Grip & Balance & Control & Stability \\
\hline $33 \%$ increase in Front Downforce Distribution & 21.19 & -62.37 & 701.17 & -197.94 \\
\hline $33 \%$ increase in Front Ride Height & 21.17 & -127.21 & 693.16 & -214.76 \\
\hline $33 \%$ increase in Rear Ride Height & 21.16 & -101.33 & 695.79 & -207.76 \\
\hline
\end{tabular}

Table 6. Percentage change in vehicle handling parameters

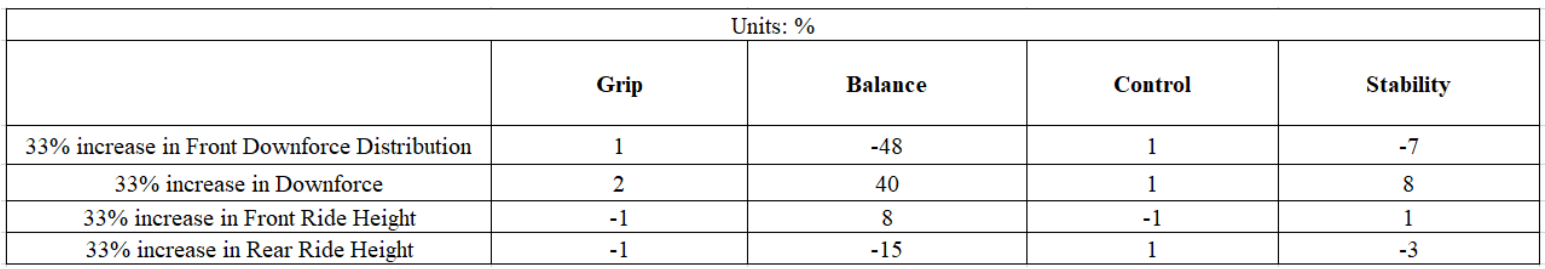


The Fig 6. shown is the pictorial representation of the above tabular column in the form of a bar chart.

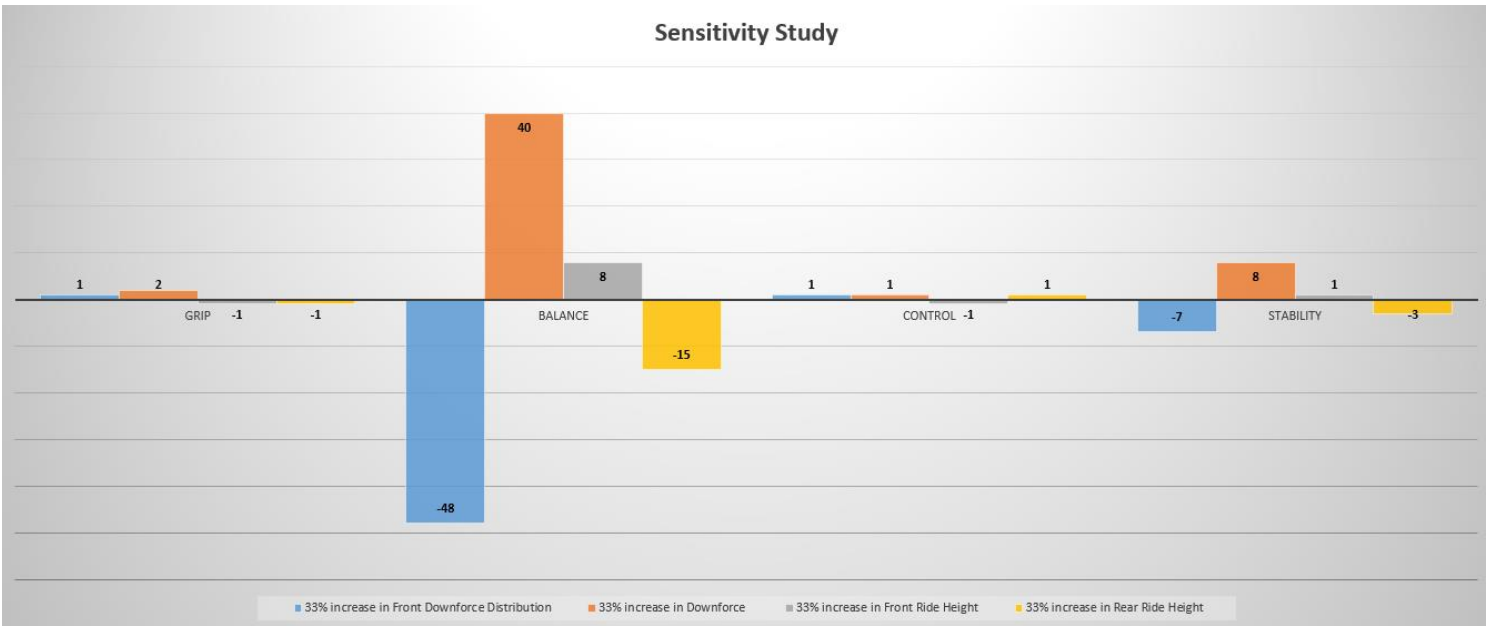

Fig 6. Bar chart of sensitivity study

Based on the results obtained in the bar chart, the following conclusions can be drawn:

1. Vehicle grip is highly sensitive to downforce.

2. Vehicle balance is highly sensitive to downforce and front downforce distribution.

3. Vehicle Control is insensitive to change in downforce, downforce distribution, front and rear ride heights.

4. Vehicle stability is sensitive to change in downforce, downforce distribution and rear ride height.

\section{Conclusion}

The findings of this paper suggests that certain vehicle handling parameters such as grip, balance and stability are sensitive to aerodynamic loads (downforce). When the front ride height increases, understeer characteristics increase, and when the rear ride height increases, oversteer traits increase. Similarly, vehicle control reduces as front ride height increases, whereas vehicle cont rol increases as rear ride height increases. When the front ride height rises, the available grip drops, then increases. Similarly, as the rear ride height increases, so does the grip. When the front ride height is raised, vehicle stability improves while maneuverability falls. Si milarly, as rear ride height rises, stability falls and maneuverability rises. 


\section{References}

1. Janssen, L. J., and H.-J. Emmelmann. "Aerodynamic Improvements - A Great Potential for Better Fuel Economy." SAE Transactions, vol. 87, pp. 1261-1269. JSTOR,1978.

2. Fu, C., Uddin, M., \& Robinson, A. C., Turbulence modelling effects on the CFD predictions of flow over a NASCAR Gen 6 racecar. Journal of Wind Engineering and Industrial Aerodynamics, 176, 98-111, 2018.

3. W. Seibert, M. Lanfrit, B. Hupertz and L. Krüger, A Best- Practice for High Resolution Aerodynamic Simulation around a Production Car Shape, 4th MIRA International Vehicle Aerodynamics Conference in Warwick, UK, October 16-17, 2002.

4. Knowles, R., Saddington, A., \& Knowles, K., On the Near Wake of Rotating, 40\%-Scale Champ Car Wheels. SAE Technical Paper Series, 2002.

5. Croner, E., Bézard, H., Sicot, C., \& Mothay, G., Aerodynamic characterization of the wake of an isolated rolling wheel. International Journal of Heat and Fluid Flow, 43, 233-243, 2013.

6. Cooper, K. R., Syms, J., \& Sovran, G., Selecting Automotive Diffusers to Maximise Underbody Downforce. SAE Technical Paper Series, 2000.

7. Cooper, K. R., Bertenyi, T., Dutil, G., Syms, J., \& Sovran, G., The Aerodynamic Performance of Automotive Underbody Diffusers. SAE Technical Paper Series, 1998.

8. Hu, X., Zhang, R., Ye, J., Yan, X., \& Zhao, Z., Influence of Different Diffuser Angle on Sedan's Aerodynamic Characteristics. Physics Procedia, 22, 239-245, 2011.

9. Thomas D. Gillespie, Fundamentals of Vehicle Dynamics, SAE International, ISBN: 978-1-56091-199-9, 1992.

10. William F. Milliken, Douglas L. Milliken, Race Car Vehicle Dynamics,SAE International, ISBN: 1-56091-526-9, 1995.

11. G Szücs and G Bári, Generating MMM diagram for defining the safety margin of self driving cars, IOP Conf. Series: Materials Science and Engineering 393 (012128), 2018.

12. K Hussain, H Rahnejat, and S Hegazy, Transient vehicle handling analysis with aerodynamic interaction, Institution of Mechanical Engineers Part K Journal of Multi-body Dynamics, March 2007.

13. Heinz Heisler, 14 - Vehicle body aerodynamics, Editor(s): Heinz Heisler, Advanced Vehicle Technology (Second Edition), Butterworth-Heinemann,Pages 584-634, ISBN 9780750651318, 2002.

14. Kachare, Shardul C., "A CFD Study of a Multi-Element Front Wing for a Formula One Racing Car" , Masters Theses, 2017

15. N. Ashton, A. West, S. Lardeau, A. Revell, Assessment of RANS and DES methods for realistic automotive models, Computers \& Fluids, Volume 128, Pages 1-15, ISSN 0045-7930, 2016

16. Ehirim, O. H., Knowles, K., \& Saddington, A. J. A Review of Ground-Effect Diffuser Aerodynamics. Journal of Fluids Engineering, 141(2), 020801, 2018

17. Meinert, F., Johannessen, K., Saito, F., Song, B. et al., "A Correlation Study of Wind Tunnels for Reduced-Scale Automotive Aerodynamic Development," SAE Int. J. Passeng. Cars - Mech. Syst. 9(2):680-694, 2016.

18. Sanwar A. Sunny, Study of wind tunnel effect on the drag coefficient (Cd) of a scaled static vehicle model compared to a Full Scale computational Fluid Dynamic Model, Asian Journal of Scientific Research, 4 (3): 236-245, 2011.

19. K.Burgin, P.C.Adey, J.P.Beatham, Wind tunnel tests on road vehicle models using a moving belt simulation of ground effect, journal of wind engineering and industrial Aerodynamics, Volume 22, Issues 2-3, 1986.

20. Marco Lanfrit, Best practice guidelines for handling Automotive External Aerodynamics with FLUENT, Fluent Deutschland GmbH Birkenweg 14a 64295 Darmstadt/Germany, Feb 2005.

21. N. Ashton, A. West, S. Lardeau, A. Revell, Assessment of RANS and DES methods for realistic automotive models, Computers \& Fluids, Volume 128, Pages 1-15, ISSN 0045-7930,2016.

22. Sudin MN, Abdullah MA, Shamsuddin SA, Ramli FR, Tahir MM, Review of research on vehicles aerodynamic drag reduction methods. Int J Mech Mechatronics Eng 14(2):35-47

23. 2014.Chowdhury H, Loganathan B, Mustary I, Moria H, Alam F, Effect of various deflectors on drag reduction for trucks. Energy Procedia 110(December 2016):561-566, 2017.

24. R.G stephens H. Babinsky, An experimental study on side skirt flow, SAE international, 2018.

25. Ortega, J. Salari, K. Brown, Aerodynamic drag reduction of class 8 heavy vehicles: a full-scale wind tunnel study, Lawrence Livermore National Laboratory. LLNL-TR-628153, 2013.

26. Dharni Vasudhevan Venkatesan, Sanjay K. E., Sujith Kumar H., Abhilash N. A., Aswin Ram D., V. R. Sanal Kuma, Studies on Race Car Aerodynamics at Wing in Ground Effect, World Academy of Science, Engineering and Technology International Journal of Mechanical and Mechatronics Engineering Vol:8, No:7, 2014.

27. Michael S. Selig, James J, Guglielmo, Andy P. Broeren and Philippe Giguere, Summary of low speed airfoil data.

28. J.J. Wang, Y.C. Li, K.-S. Choi, Gurney flap—Lift enhancement, mechanisms and applications, Progress in Aerospace Sciences, Volume 44, Issue 1,Pages 22-47, ISSN 0376-0421, 2008. 